\title{
Managing peptic ulcer and gastroesophageal reflux disease in elderly Chinese patients - focus on esomeprazole
}

This article was published in the following Dove Press journal:

Clinical Interventions in Aging

24 October 2013

Number of times this article has been viewed

\section{Raymond SY Tang Justin CYWu}

Institute of Digestive Disease, The Chinese University of Hong Kong, Prince of Wales Hospital, Shatin, New Territories, Hong Kong
Correspondence: Justin $\mathrm{CY} \mathrm{Wu}$

Institute of Digestive Disease, Department of Medicine and Therapeutics, The Chinese University of Hong Kong, Prince of Wales Hospital, 9/F, Clinical Science Building, 30-32 Ngan Shing Street, Shatin, New Territories, Hong Kong

Tel +85226323593

Fax +852 26472337

Email justinwu@cuhk.edu.hk
Abstract: Peptic ulcer disease (PUD) and gastroesophageal reflux disease (GERD) are not uncommon in elderly patients. Clinical presentations of these acid-related disorders may be atypical in the geriatric population. Older individuals are at increased risk for poor outcomes in complicated PUD and for development of GERD complications. Multiple risk factors (eg, Helicobacter pylori [HP], use of nonsteroidal anti-inflammatory drugs [NSAIDs], aspirin) contribute to the development of PUD. Recent data has shown that HP-negative, NSAID-negative idiopathic peptic ulcers are on the rise and carry a higher risk of recurrent ulcer bleeding and mortality. Effective management of PUD in the geriatric population relies on identification and modification of treatable risk factors. Elderly patients with GERD often require long-term acid suppressive therapy. Proton pump inhibitors (PPI) including esomeprazole are effective in the treatment of reflux esophagitis, maintenance of GERD symptomatic control, and management of PUD as well as its complications. Potential safety concerns of long-term PPI use have been reported in the literature. Clinicians should balance the risks and benefits before committing elderly patients to long-term PPI therapy.

Keywords: elderly patients, peptic ulcer disease, gastroesophageal reflux disease, proton pump inhibitor, esomeprazole

\section{Introduction}

Peptic ulcer disease (PUD) and gastroesophageal reflux disease (GERD) are both common acid-related disorders. Management of acid-related disorders in the elderly patient population represents a unique challenge as the epidemiology, clinical presentations, and outcomes may be different from their younger counterparts. ${ }^{1,2}$ There is also a higher tendency for older individuals to have multiple medical comorbidities (eg, cardiovascular disease, cerebral vascular disease, diabetes, chronic kidney disease, degenerative joint disease) requiring them to use medications (eg, aspirin, nonsteroidal anti-inflammatory drugs [NSAIDs]) that increase the risk of upper gastrointestinal (GI) injury. Although acid suppressive therapy has become the cornerstone in the management of PUD and GERD, the safety and tolerability of various acid suppressive agents deserve special attention in the geriatric population. This article aims to review the key issues in the management of PUD and GERD in elderly Chinese patients and the use of proton pump inhibitors (PPI) in acid-related disorders with a focus on esomeprazole.

\section{PUD}

\section{Epidemiology and risk factors}

Although the incidence of uncomplicated PUD has decreased in recent years in the general population, elderly patients remain at high risk for PUD and its complications such as bleeding or perforation. ${ }^{3-5}$ 
Old age and the presence of comorbidities have been consistently shown to be risk factors for poor outcomes in patients with complicated PUD..$^{5-9}$ In a large population-based study of 7,232 patients with bleeding peptic ulcer, the standardized 30-day mortality among patients older than 80 years was $16.9 \%$ compared with $4.3 \%$ among patients younger than 65 years. ${ }^{6}$ Another study reported a higher annual incidence of perforation in PUD patients who were greater than 65 years old. ${ }^{7}$ In a population-based study including patients with peptic ulcer bleeding and perforation, diabetes was associated with increased short-term mortality. ${ }^{8}$ In a retrospective review of 9,375 Chinese patients with peptic ulcer bleeding in a tertiary center, 577 patients died, with a majority of them (79.7\%) dying of non-bleeding related causes (eg, multiorgan failure, pulmonary conditions, and terminal malignancy). ${ }^{9}$ This has significant implications in the elderly population with PUD as they often have cardiovascular, pulmonary, metabolic, or renal comorbidities.

Helicobacter pylori (HP) infection, the use of NSAIDs, and the use of aspirin and/or other antithrombotic drugs are important risk factors for PUD and its complications in the geriatric population. ${ }^{4,10}$ However in the last decade, there is also emerging evidence to suggest that the incidence of HP-negative, NSAID-negative, idiopathic peptic ulcers is on the rise. ${ }^{11}$ Elderly patients may be at higher risk for the HP-negative, NSAID-negative ulcers as reduction in gastric or duodenal mucosal barriers often occurs with aging. ${ }^{1}$

\section{Clinical presentations}

Manifestations of PUD in elderly patients may be atypical. In a prospective study with 277 patients with PUD, two-thirds of the patients aged more than 60 years reported vague abdominal pain as the main symptom. ${ }^{12}$ Nonspecific symptoms of PUD often lead to delayed diagnosis and development of PUD complications in the geriatric population. ${ }^{1}$

\section{Management of HP related ulcers}

In a study focusing on elderly peptic ulcer patients, $70 \%$ of the elderly patients were found to be HP positive. ${ }^{4}$ A meta-analysis of epidemiologic studies conducted in a Mainland Chinese population reported a HP infection rate of $58 \% .{ }^{13}$ In a recent population-based study from Shanghai, People's Republic of China, PUD was found in $17.2 \%$ of the 1,022 analyzed patients and HP infection was found in $92.6 \%$ of patients with PUD. ${ }^{14}$ With a population of 1.3 billion in Mainland China, the burden of HP infection and its related complications is significant. Untreated HP-associated peptic ulcers tend to recur. ${ }^{15}$ Hence, it is important to test and treat HP infection in elderly patients who present with PUD.

Treatment of HP in elderly patients is similar to that in their younger counter parts, but attention should be given to the local antibiotic resistance of the HP strains, as well as the compliance and tolerability of the regimens in the elderly patients. Management guidelines from the Maastricht III Consensus Report and the American College of Gastroenterology in 2007 recommend first-line treatment of HP infection with clarithromycin-based triple therapy (PPI, clarithromycin, and amoxicillin or metronidazole) for 7 to 14 days or bismuthbased quadruple therapy (PPI, bismuth, metronidazole, and tetracycline) for 10 to 14 days. ${ }^{16,17}$ Unfortunately, HP treatment eradication rates are far from ideal in these established regimens. Major clinical studies reported intention-to-treat HP eradication rates of only $70 \%$ to $80 \%$ regarding these regimens. ${ }^{18,19}$ Data from meta-analyses regarding first-line triple therapy for HP showed that increasing the duration of triple therapy from 7 days to 14 days increased the eradication rate by $5 \%$ to $9 \%$. $^{20,21}$

The prevalence of antibiotic resistance in HP must be taken into consideration when choosing among the various eradication regimens to maximize the chance of success. The rise in clarithromycin resistance may explain the high failure rate of clarithromycin-based regimens in some studies. ${ }^{22}$ On the other hand, metronidazole resistance may be more relative, and can sometimes be overcome by using a higher dose of metronidazole or using it in a quadruple regimen with PPI, bismuth, and tetracycline. ${ }^{23}$ In areas with high clarithromycin and metronidazole resistance, bismuth-based quadruple therapy should be used for first-line therapy. ${ }^{16,17}$ Salvage regimens containing levofloxacin or rifabutin can be considered, if a patient fails regimens containing clarithromycin and metronidazole. ${ }^{16,17}$ Recently, four-drug regimens (concomitant or sequential) besides the bismuth-based quadruple regimen have been studied and may be alternatives to traditional triple therapy in regions with suboptimal HP eradication rates. $^{24,25}$

Since HP eradication regimens involve multiple antibiotics, monitoring for compliance and potential drug interactions with patients' routine medications are particularly important in the geriatric population. When elderly patients have persistent HP infection, the possibility of noncompliance should be explored.

\section{Management of NSAID related ulcers}

Elderly patients often develop degenerative joint diseases during the aging process. NSAIDs, which are often prescribed 
for pain relief, have emerged as one of the most important causes of recurrent peptic ulcer disease and its complications in many developed countries as the incidence of HPassociated ulcers decline. Up to $25 \%$ of chronic NSAID users develop ulcer disease, of which $2 \%$ to $4 \%$ will have complications such as bleeding or perforation. ${ }^{26,27}$

Multiple risk factors for NSAID-related GI complications have been described, including advanced age, a prior GI event, high-dose NSAID therapy, concomitant use of low-dose aspirin, anticoagulants, or corticosteroids, and cardiovascular diseases. ${ }^{27,28}$ Mixed results have been reported regarding HP infection in ulcer risk of NSAID users. ${ }^{27}$ Nevertheless, HP infection likely increases the risk of NSAID related GI complications given data from a randomized study showing that HP eradication significantly reduces the risk of ulcers for patients on NSAIDs. ${ }^{29}$

Ideally, the best preventive strategy is to avoid NSAIDs entirely in patients with history of NSAID related ulcers or complications. However, NSAIDs are often prescribed in elderly patients with chronic joint pain, placing them at higher risk for PUD. Thus co-therapy with a gastroprotective agent is desirable. Systematic reviews of multiple randomized controlled studies have shown that PPI, misoprostol, and double-dose histamine-2-recpetor antagonist (H2RA) are effective at preventing chronic NSAID related endoscopic gastric and duodenal ulcers. ${ }^{30-32}$

Until recently, substitution of cyclooxygenase-2 (COX-2) selective NSAIDs for nonselective NSAIDs in patients at risk for GI injury has been a popular option. However, emerging data on cardiovascular risks of COX-2 inhibitors and other nonselective NSAIDs have raised concerns about their use. Data from systematic reviews of observational studies and randomized trials showed that both COX-2 inhibitors and nonselective NSAIDs are associated with increased cardiothrombotic risk, with the probable exception of naproxen. ${ }^{33,34}$ Elderly patients may be particularly affected as they often have underlying ischemic heart disease or diabetes, putting them at higher risk for cardiovascular thrombotic events. For patients who require chronic NSAID use, the patient's cardiovascular risk will affect the initial choice of NSAID (eg, naproxen versus others), and the patient's GI risk factors will dictate the type of GI protection strategy (see Table 1). ${ }^{27}$

\section{Management of peptic ulcers in patients on aspirin and/or other antithrombotic drugs}

Cardiovascular and cerebral vascular diseases are not uncommon in the geriatric population. These patients are usually on long-term aspirin and/or other antithrombotic drug therapy, placing them at high risk for GI complications. Indeed, lowdose aspirin has emerged as one of the most important causes of peptic ulcer bleeding in developed countries. Advanced age ( $>70$ years of age), prior history of ulcer bleeding, dose of aspirin, concomitant use of NSAIDs, and HP infection have been consistently shown to be risk factors for upper GI bleeding in aspirin users. ${ }^{35,36}$ In a recent study of high risk myocardial infarction survivors on aspirin, additional risk factors for GI bleeding, including use of dual antiplatelet therapy, concomitant anticoagulants, history of alcohol abuse, New York Heart Association class III or IV, diabetes, renal failure, male sex, and non-white race have been identified. ${ }^{37}$ The abovementioned risk factors are relevant to elderly patients since many of them would have more than one of the risk factors.

The main strategies for reducing upper GI bleeding in aspirin users focus on elimination of risk factors and cotherapy with a gastroprotective agent. In a randomized trial comparing HP eradication therapy alone to maintenance treatment with a PPI in aspirin users with HP infection and prior ulcer bleeding in Hong Kong, recurrent ulcer bleeding occurred in $1.9 \%$ of patients in the HP eradication therapy group and in $0.9 \%$ of the PPI group. ${ }^{38}$ In another recently published prospective cohort study of three cohorts of aspirin users in Hong Kong (HP-eradicated cohort, HP-negative

Table I Ulcer prevention strategy according to cardiovascular and gastrointestinal risks in patients on chronic NSAID therapy

\begin{tabular}{lll}
\hline & GI risk & \\
\cline { 2 - 3 } & Low $^{\mathbf{a}}$ & Moderate $^{\text {b }}$ \\
\hline CV risk: low & Nonselective NSAID & NSAID and PPI or misoprostol, \\
(low-dose aspirin not needed) & & or COX-2 inhibitor alone \\
CV risk: high & Naproxen and PPI or & Naproxen and PPI or misoprostol \\
(low-dose aspirin needed) & misoprostol & Avoid NSAID and COX-2 \\
\hline
\end{tabular}

Notes: GI risk factors: age $>65$ years, high-dose NSAID therapy, previous history of peptic ulcer, concomitant use of aspirin, corticosteroids, or anticoagulants. ${ }^{2}$ Low GI risk = no Gl risk factor; 'boderate GI risk = one to two GI risk factors (eg, prior uncomplicated peptic ulcer); chigh Gl risk = more than two $\mathrm{Gl}$ risk factors or prior complicated peptic ulcer. Adapted by permission from Macmillan Publishers Ltd: American Journal of Gastroenterology. Lanza FL, Chan FK, Quigley EM; Practice Parameters Committee of the American College of Gastroenterology. Guidelines for prevention of NSAID-related ulcer complications. Am J Gastroenterol. 2009; 104(3):728-738, copyright 2009. ${ }^{27}$ Abbreviations: COX-2 inhibitor, cyclooxygenase-2 inhibitor; CV, cardiovascular; GI, gastrointestinal; NSAID, nonsteroidal anti-inflammatory drug; PPI, proton pump inhibitor. 
cohort, and average risk cohort without prior ulcer or ulcer bleeding), the authors reported the rate of ulcer bleeding was 0.97 per 100 patient-years in the HP-eradicated cohort, 5.22 per 100 patient-years in the HP-negative cohort, and 0.66 per 100 patient-years in the average risk cohort. ${ }^{39}$ Among aspirin users with prior ulcer bleeding, data from this study suggested that the long-term ulcer bleeding risk is low after HP eradication. ${ }^{39}$ The substitution of clopidogrel for aspirin has been shown to be inferior to the combination of aspirin and PPI in two randomized trials from Hong Kong in patients with prior ulcer bleeding, and is no longer recommended as a strategy to reduce risk of recurrent ulcer bleeding in highrisk aspirin users by an updated joint consensus report by the American College of Cardiology Foundation, American College of Gastroenterology, and American Heart Association in $2008 .^{40-42}$

Dual antiplatelet therapy (eg, aspirin and clopidogrel) has been increasingly used in patients with coronary artery stents. Randomized studies have shown an increased risk of major GI bleeding in patients receiving dual antiplatelet therapy for acute coronary syndrome or atrial fibrillation. ${ }^{43,44}$ The updated joint consensus report in 2008 by the American College of Cardiology Foundation, American College of Gastroenterology, and American Heart Association recommended routine prophylactic PPI use in patients on dual antiplatelet therapy. ${ }^{42}$ Subsequently, results from a randomized trial confirmed the efficacy of prophylactic PPI in reducing upper GI bleeding associated with dual antiplatelet therapy. ${ }^{45}$ However, concerns do exist in the use of PPI co-therapy. Recently, based on findings from in vitro studies and observational studies, there have been concerns about potentially unfavorable interaction between PPI and clopidogrel. ${ }^{46-48}$ A significant increase in the risk of myocardial infarction in patients receiving concomitant PPI was found in a meta-analysis of cardiovascular outcomes in patients receiving clopidogrel with or without PPI. ${ }^{49}$ However, on subgroup analysis, data from randomized trials or propensity-matched participants did not show such association. ${ }^{49}$ To date, data from the only double-blinded randomized trial designed to address whether concomitant use of PPI with clopidogrel would adversely affect cardiovascular outcome did not find apparent cardiovascular interaction between clopidogrel and omeprazole. ${ }^{45}$ For patients on dual antiplatelet therapy, strategies to prevent recurrent PUD and its complications center on balancing the bleeding and thrombotic risks of individual patients. ${ }^{50,51}$ For patients with high bleeding risk and low thrombotic risk patients, PPI prophylaxis with standard dual antiplatelet therapy can be considered. ${ }^{51}$ For patients with both high bleeding and thrombotic risks, staggered administration (12 hours apart) of PPI and clopidogrel can be considered, with avoidance of omeprazole as choice of PPI. Alternate antiplatelet regimens should be considered. ${ }^{51}$

\section{Management of HP-negative, NSAID-negative ulcers}

Emerging data has suggested that the proportion of HPnegative, NSAID-negative idiopathic peptic ulcers appears to be on the rise. Because reductions in gastric and duodenal barriers often occur in the aging process, elderly patients are at higher risk for HP-negative, NSAID-negative ulcers. ${ }^{1}$ In a pooled analysis with more than 2,900 patients, $27 \%$ of duodenal ulcers were not associated with HP infection or NSAID use. ${ }^{52}$ In a prospective study of Chinese patients with bleeding ulcers in Hong Kong, the authors reported an increase in the proportion of HP-negative, NSAID-negative idiopathic ulcers from $4.2 \%$ in $1997-1998$ to $18.8 \%$ in $2000 .{ }^{11}$ Worse clinical outcomes have also been reported in patients with HP-negative, NSAID-negative idiopathic ulcers. In a recent 7-year prospective cohort study from Hong Kong, the 7-year cumulative incidence of recurrent ulcer bleeding was reported to be significantly higher in the HP-negative, NSAID-negative idiopathic ulcer group (42.3\%) when compared to the HP-positive, NSAID-negative ulcer group who received eradication therapy $(11.2 \%) .{ }^{53}$ A significantly higher mortality was also reported in the HP-negative, NSAID-negative idiopathic ulcer cohort over the study period when compared to the HP-positive cohort $(87.6 \%$ versus $37.3 \%){ }^{53}$ Although long-term gastroprotective therapy (eg, PPI) has been proposed for patients with bleeding related to HP-negative, NSAID-negative idiopathic ulcers, there has been no established guideline in this area. Recent data from a prospective study on the long-term clinical outcomes of gastroprotective therapy (PPI or H2RA) in patients with HPnegative, NSAID-negative idiopathic bleeding ulcers in Hong Kong suggested that gastroprotective agents did not reduce the risk of recurrent bleeding or mortality for patients with HP-negative, NSAID-negative idiopathic bleeding ulcers. ${ }^{54}$ Of note, the incidence rate of death was significantly higher during the gastroprotective agent-exposed period than that during the nonexposed period (21.8 per 100 person-years versus 13.8 per 100 person-years). However, after adjusting for possible confounders including age, American Society of Anesthesiology classification grade, location of ulcer, and ulcer bleeding after hospitalization, gastroprotective agent use was not shown to be an independent predictive factor of all-cause mortality. ${ }^{54}$ This finding may suggest that 
gastroprotective agents may be preferentially prescribed to older and sicker patients in this cohort. Further research will be needed to better define the optimal long-term management strategy for patients with HP-negative, NSAID-negative idiopathic ulcers.

\section{GERD}

\section{Epidemiology and risk factors}

GERD is a chronic relapsing peptic disorder characterized by recurrent acid reflux symptoms and/or extra-esophageal manifestations. ${ }^{55}$ Although GERD is a common GI complaint, it is frequently underdiagnosed and undertreated in elderly patients. ${ }^{2}$ While the prevalence of GERD is about $10 \%-20 \%$ in Western countries, the majority of the Asian epidemiologic studies have reported a lower prevalence of less than $10 \%{ }^{56-58}$ Dedicated studies of GERD in elderly patients are limited. Based on data from studies of elderly patients in the USA, the incidence of symptomatic GERD was reported to range from $14 \%-20 \%$ and did not appear to increase with age. ${ }^{59,60}$ On the other hand, GERD complications such as esophagitis, stricture, and Barrett's esophagus were reported to be more common in older people. In a USA study, significantly more cases of erosive esophagitis and Barrett's esophagus were diagnosed in patients aged 60 years or above $(81 \%)$ when compared to younger patients (47\%) ${ }^{61}$ In another study of 194,527 patients from the hospitals of the Department of Veteran Affairs in the USA, older age, male sex, and white ethnicity were reported to be risk factors in the development of severe forms of GERD including esophageal erosions, ulcers, or strictures. ${ }^{62}$ Although impaired esophageal barriers to acid reflux may occur due to aging, the cumulative injury of acid to the esophageal mucosa for a prolonged period may be the reason for the increased severity of GERD in elderly patients. ${ }^{2}$ Risk factors for GERD in Asian patients appear to be similar to those reported in Western populations, with male sex, smoking, high-fat diet, obesity, stress, and major life events being the most consistent ones. ${ }^{56}$

\section{Pathophysiology}

Multiple mechanisms such as transient lower esophageal sphincter relaxation (TLESR) with excessive acid reflux, hiatus hernia, impaired esophageal peristalsis, and weak lower esophageal sphincter (LES) contribute to the development of GERD. ${ }^{2,56}$ TLESR with excessive acid reflux has been shown to be the most important mechanism. ${ }^{2,56}$ In elderly patients, age itself does not appear to cause decrease in LES pressure. ${ }^{2}$ Rather, geriatric patients often take medications known to reduce LES pressure (eg, nitrates, calcium channel blockers, benzodiazepines, anticholinergics, antidepressants). ${ }^{2}$ The prevalence of hiatus hernia was reported to increase with age. ${ }^{63}$ When compared to a Western population, the prevalence of hiatus hernia was found to be lower in Asian populations. $^{64}$

In both Western and Asian populations, obesity has been shown to have a strong association with GERD. ${ }^{65,66}$ In a recent study from Hong Kong, body mass index and waist circumference were shown to correlate with TLESR and gastroesophageal pressure gradient in GERD patients. ${ }^{66}$ The rise in prevalence of GERD in Asian populations may be related to the increase in obesity. ${ }^{56}$

There has been controversy in the role of HP in GERD between Western and Asian studies. A negative association between HP infection and GERD was reported in many Asian studies. ${ }^{56,67} \mathrm{HP}$ infection in GERD patients was reported to be lower than in those without reflux symptoms in Asia, with prevalence ranging from $25 \%$ to $35 \%{ }^{68,69}$ In HP infected patients with corpus gastritis and atrophic gastritis, eradication of HP was found to be associated with recovery of gastric acid secretion and development of reflux esophagitis. ${ }^{70}$ In GERD patients infected with HP, any protective effect of HP infection may be offset by the presence of more severe LES dysfunction and esophageal dysmotility. ${ }^{71}$

\section{Clinical presentations}

Elderly patients with GERD tend to present less frequently with typical GERD symptoms such as heartburn or acid regurgitation. ${ }^{2,72}$ In GERD patients aged 65 years or older, other symptoms such as weight loss, anorexia, dysphagia, or vomiting were reported to increase with age..$^{72,73}$ GERD complications such as esophagitis, strictures, or Barrett's esophagus have been reported to be more common in older individuals. ${ }^{2}$ In Asian populations, chest pain and atypical esophageal symptoms were reported to be common presenting symptoms of GERD. ${ }^{56} \mathrm{~A}$ study of Chinese patients with noncardiac chest pain reported that symptomatic response to PPI predicts abnormal acid reflux in patients without esophagitis. $^{74}$

\section{Management}

GERD runs a chronic relapsing course and long-term therapy is needed for the majority of patients. Although treatment principles in elderly GERD patients are similar to those of younger adult patients, clinicians should be reminded that older individuals are more likely to have esophagitis or other GERD complications that often require more aggressive treatment., ${ }^{2,72}$ While lifestyle modifications, antacids, 
alginic acid, and H2RA are helpful in the management of milder GERD symptoms, PPI is the standard therapy for GERD patients who require long-term symptomatic relief or develop complications such as erosive esophagitis, strictures, and Barrett's esophagus. ${ }^{2}$ PPI has been shown to be effective in providing symptomatic relief of GERD and healing of esophagitis in different age groups. ${ }^{75}$ As geriatric patients often require long term PPI therapy for symptomatic relief or treatment of GERD complications, the benefits and potential risks of chronic PPI use will be further discussed below.

\section{Use of PPIs in acid-related disorders - with a focus on esomeprazole}

PPIs play a major role in the current management of acid-related disorders including PUD and GERD. PPIs reduce gastric acid secretion by inhibiting the proton pump $(\mathrm{H}+/ \mathrm{K}+$-ATPase $)$ in the gastric parietal cells.$^{76}$ Omeprazole is the first PPI developed for clinical use. ${ }^{77}$ Esomeprazole, which is the (S)-isomer of omeprazole, is the first PPI to be developed as an optical isomer with the goal of improving the pharmacokinetics and the acid suppression characteristics of omeprazole. ${ }^{77}$ Esomeprazole is highly protein-bound in plasma and has a high chiral stability with a very low inversion rate to the R-isomer at $0.4 \%{ }^{78}$ Because esomeprazole absorption is delayed and decreased when administered before a high fat meal, it is generally advised to be taken 30 minutes to 1 hour before meals. ${ }^{79}$ When compared to omeprazole, a higher area under the plasma drug concentration versus time curve is achieved by esomeprazole through decreased first-pass metabolism and systemic clearance. ${ }^{78}$ Esomeprazole is metabolized by two cytochrome P450 isoenzymes, CYP2C19 and CYP3A4, with CYP2C19 being the major metabolic pathway. ${ }^{77}$ Dosing adjustment of esomeprazole is not required in elderly patients, patients with renal impairment, or mild hepatic impairment. ${ }^{80}$ However, dosing should be reduced in patients with severe liver dysfunction. ${ }^{80}$

\section{Healing of reflux esophagitis}

The efficacy of esomeprazole in healing reflux esophagitis was evaluated in multiple randomized clinical trials. ${ }^{81-88}$ Healing rates of esophagitis by esomeprazole were shown to be either equivalent or statistically higher at 4 weeks when compared with omeprazole, lansoprazole, and pantoprazole. The esophagitis healing rate at 8 weeks is up to $96 \% .^{81-88}$

\section{Maintenance of healing of esophagitis}

Esomeprazole is effective in the maintenance of the healing of reflux esophagitis. In a 12-month noncomparative study, esomeprazole at $40 \mathrm{mg}$ daily was shown to maintain the healing of esophagitis in $89.4 \%$ of patients at 12 months. ${ }^{89}$ When compared to lansoprazole and pantoprazole, esomeprazole keeps a significantly higher proportion of patients with healed esophagitis in remission. ${ }^{90-92}$

\section{Symptomatic control of GERD without esophagitis}

Esomeprazole at $20 \mathrm{mg}$ or $40 \mathrm{mg}$ per day for 4 weeks has been shown to provide effective symptomatic control in patients without esophagitis when compared to placebo or omeprazole. ${ }^{93,94}$ In a systemic review of 17 studies, ondemand esomeprazole and other PPIs are effective in longterm management of GERD without esophagitis. ${ }^{95}$

\section{Use of esomeprazole in PUD}

The efficacy of esomeprazole has been demonstrated in HP eradication therapy, healing of NSAID or aspirin related peptic ulcers, and reduction of early recurrent bleeding in peptic ulcers after successful endoscopic therapy. In PPIbased triple therapy regimens utilizing esomeprazole $20 \mathrm{mg}$ twice daily or $40 \mathrm{mg}$ daily for HP eradication, a 7-day regimen with esomeprazole $20 \mathrm{mg}$ twice daily, amoxicillin $1 \mathrm{~g}$ twice daily, and clarithromycin $500 \mathrm{mg}$ twice daily achieved intention-to-treat eradication rates of $86 \%-90 \%$ and per protocol eradication rates of $90 \%-91 \%$ in duodenal ulcer patients in Canada and Europe, while a 10-day regimen with esomeprazole $40 \mathrm{mg}$ daily, amoxicillin $1 \mathrm{~g}$ twice daily, and clarithromycin $500 \mathrm{mg}$ twice daily achieved intention-to-treat eradication rates of $77 \%-78 \%$ and per protocol eradication rates of $84 \%-85 \%$ in duodenal ulcer patients in the USA. ${ }^{96}$ In patients receiving an NSAID or COX-2 inhibitor with gastric ulcer, esomeprazole ( $20 \mathrm{mg}$ daily or $40 \mathrm{mg}$ daily) resulted in a significantly higher ulcer-healing rate $(88.4 \%$ and $91.5 \%$, respectively) when compared to ranitidine $150 \mathrm{mg}$ twice daily. ${ }^{97}$ Esomeprazole was also demonstrated to be effective in preventing the development of ulcers in long-term users of NSAIDs and COX-2 inhibitors in two large randomized trials. ${ }^{98}$ In HP-negative patients on longterm low-dose aspirin, esomeprazole significantly reduces the development of peptic ulcers when compared to placebo. ${ }^{99}$ High-dose intravenous esomeprazole after successful endoscopic hemostasis was shown to reduce recurrent peptic ulcer bleeding at 72 hours with sustained benefits up to 30 days in a multicenter randomized trial. ${ }^{100}$ 


\section{Safety and tolerability}

Esomeprazole, as with other PPIs, is generally well-tolerated, with common side effects such as diarrhea, nausea, abdominal pain, flatulence, or headache occurring in less than $5 \%$ of patients. ${ }^{77}$ As elderly patients with acid-related disorders often require long-term PPI therapy, safety of chronic PPI use in this population deserves special attention.

Chronic PPI use may interfere with calcium absorption due to hypochlorhydria, but may also reduce bone resorption through inhibition of osteoclastic activity. ${ }^{101,102}$ Increasing clinical evidence has shown a positive association of chronic PPI use with fractures. A large nested case-control study suggested that long-term PPI use $>1$ year is associated with increased risk of hip fractures in patients $>50$ years old. ${ }^{103}$ The strength of association increases with longer duration of PPI therapy and high-dose PPI use. ${ }^{103} \mathrm{~A}$ recent meta-analysis of eleven observational studies reported increased risk of hip, wrist, and spine fractures in chronic PPI users. ${ }^{104}$ Thus, in elderly patients with other risk factors for fractures (eg, osteoporosis, prior fractures), long-term ( $>1$ year) high-dose PPI should be avoided. Calcium and vitamin D supplements may be considered in high risk patients.

Increased risk of certain infections (eg, enteric infections, spontaneous bacterial peritonitis in cirrhotic patients, and respiratory infections) has been reported with PPI use. ${ }^{105-116}$ A large population-based case-control study suggested an increased risk of Campylobacter and Salmonella gastroenteritis in PPI users, but not in H2RA users. ${ }^{105}$ Growing evidence based on initial population-based case-control studies and three recent meta-analyses of observational studies suggest that PPI use is associated with an increased risk of Clostridium difficile infection and associated diarrhea. ${ }^{106-109}$ The association was noted to be greater in PPI users than in H2RA users. ${ }^{108}$ Strategies to minimize the risk of $C$. difficile infection in the elderly population would include avoidance of high-dose PPI or temporary withdrawal of PPI in high-risk patients (eg, patients with chronic kidney disease, inflammatory bowel disease, malignancy, or immunosuppression).

In cirrhotic patients with ascites, initial retrospective case-control studies have yielded inconsistent results on the risk of spontaneous bacterial peritonitis and PPI use, but a subsequent meta-analysis reported a positive association between PPI use and increased risks of spontaneous bacterial peritonitis. ${ }^{110-112}$ Hence, PPI should be used judiciously with clearly justified indication in this group of patients.

Observational studies have suggested a possible association between PPI use and increased risk of community acquired pneumonia (CAP). ${ }^{113-115}$ The reported association remains controversial since the increased risk of CAP was mostly noted in patients with recent initiation of PPI, but not in patients with prolonged PPI use. ${ }^{14,115}$ The observed associations between recent initiation of PPI and the increased risk of CAP may be confounded. ${ }^{116}$

Malabsorptions of certain nutrients and medications have been described in chronic PPI users. Chronic PPI use, but not past or short-term use, has been reported to be associated with vitamin B12 deficiency. ${ }^{117-119}$ Since older individuals with malnourishment are at higher risk for vitamin B12 deficiency, monitoring of B12 level should be considered in these high-risk patients on long-term PPI therapy. Hypomagnesemia in long-term PPI users due to reduced intestinal magnesium absorption has been reported. ${ }^{120,121}$ This has implications in geriatric populations since elderly patients are often taking other medications that may predispose them to hypomagnesemia (eg, digoxin or diuretics). Checking of magnesium level before and during chronic PPI therapy should be considered. Absorption of certain medications often requires an optimal gastric acidity. Malabsorption of thyroxine has been described in patients treated with acid suppressive drugs. ${ }^{122}$ In patients on thyroxine therapy, a need for a higher dose of thyroxine was observed in patients on PPI therapy. ${ }^{122}$

The safety of chronic PPI use in HP-infected patients remains a subject of debate. It has been suggested that HPinfected patients on chronic PPI therapy have a propensity to develop atrophic gastritis, placing them at risk for gastric malignancy. ${ }^{123}$ Progression of atrophic gastritis can be prevented by eradication of HP. ${ }^{124}$ In Asian countries where the prevalence of HP infection is high, HP eradication before starting long-term PPI in GERD patients should be considered. ${ }^{125}$

The potential unfavorable interaction between PPI and clopidogrel has been discussed previously in the PUD section of this article. In vitro studies reported that some PPIs may reduce the antiplatelet activity of clopidogrel by inhibiting the cytochrome P450 enzyme, CYP2C 19. ${ }^{46,47}$ However, whether in vitro findings have good correlation with actual clinical outcomes remains controversial. In the only randomized trial designed to address the cardiovascular outcomes in patients treated with both clopidogrel and PPI, PPI use did not seem to negatively impact the cardiovascular outcomes ${ }^{45}$ In a recent randomized trial designed to study the effects of four different PPIs (omeprazole, esomeprazole, lansoprazole, and dexlansoprazole) on the steady-state pharmacokinetics and pharmacodynamics of clopidogrel, all four PPIs were shown to reduce the active metabolite of clopidogrel. ${ }^{126}$ 
Table 2 Balancing the benefits and risks of long-term proton pump inhibitor use in elderly patients

\begin{tabular}{ll}
\hline Benefits & Potential risks \\
\hline - Part of Helicobacter pylori eradication therapy & - Risk of enteric infections (eg, Clostridium difficile) \\
- Healing of peptic ulcer & - Risk of community acquired pneumonia \\
- Co-therapy for chronic NSAID user with GI risk factors & - Risk of malabsorption of nutrients (eg, vitamin BI2, magnesium, calcium, iron) \\
- Co-therapy for chronic aspirin user with prior complicated PUD & - Risk of malabsorption of certain medications (eg, thyroxine) \\
- Symptomatic control for GERD & - Risk of atrophic gastritis in Helicobacter pylori-infected GERD patients \\
- Therapy for complicated GERD (eg, reflux esophagitis, peptic & - Risk of unfavorable interaction between certain PPIs and clopidogrel \\
stricture, Barrett's esophagus) & \\
\hline
\end{tabular}

Abbreviations: GERD, gastroesophageal reflux disease; NSAID, nonsteroidal anti-inflammatory drug; PPI, proton pump inhibitor; PUD, peptic ulcer disease; GI, gastrointestinal.

Omeprazole and esomeprazole were shown to significantly reduce the vasodilator-stimulated phosphoprotein platelet reactivity index, and with a stronger inhibitory effect when compared to lansoprazole and dexlansoprazole. ${ }^{126}$ Avoidance of concomitant use of omeprazole or esomeprazole with clopidogrel has been recommended by the United States Food and Drug Administration and the European Medicines Agency.

\section{Conclusion}

Acid-related disorders, including PUD and GERD, are common and often present with atypical symptoms in elderly patients. Poorer clinical outcomes in PUD and increased incidence of GERD complications are frequently observed in older individuals. Being the cornerstone in acid suppressive therapy, PPIs are generally well-tolerated in the elderly population. However, potential safety concerns do exist for long-term and high-dose PPI use. Clinicians should balance the risks and benefits of chronic PPI therapy in older patients and use the lowest effective dose when possible (see Table 2).

\section{Disclosure}

Justin CY Wu is an invited speaker of the following companies: AstraZeneca, Abbott, Given Imaging, Lundbeck and Takeda. He is also serving in the advisory board of Takeda and Abbott. The authors report no other conflicts of interest in this work.

\section{References}

1. Pilotto A, Franceschi M, Maggi S, Addante F, Sancarlo D. Optimal management of peptic ulcer disease in the elderly. Drugs Aging. 2010;27(7):545-558.

2. Richter JE. Gastroesophageal reflux disease in the older patient: presentation, treatment, and complications. Am J Gastroenterol. 2000;95(2):368-373.

3. Malfertheiner P, Chan FK, McColl KE. Peptic ulcer disease. Lancet. 2009;374(9699):1449-1461.

4. Pilotto A. Helicobacter pylori-associated peptic ulcer disease in older patients: current management strategies. Drugs Aging. 2001;18(7):487-494.
5. Lau JY, Sung J, Hill C, Henderson C, Howden CW, Metz DC. Systematic review of the epidemiology of complicated peptic ulcer disease: incidence, recurrence, risk factors and mortality. Digestion. 2011;84(2):102-113.

6. Christensen S, Riis A, Nørgaard M, Sørensen HT, Thomsen RW. Shortterm mortality after perforated or bleeding peptic ulcer among elderly patients: a population-based cohort study. BMC Geriatr. 2007;7:1-8.

7. Taha AS, Angerson WJ, Prasad R, McCloskey C, Gilmour D, Morran CG. Clinical trial: the incidence and early mortality after peptic ulcer perforation, and the use of low-dose aspirin and nonsteroidal anti-inflammatory drugs. Aliment Pharmacol Ther. 2008;28(7):878-885.

8. Thomsen RW, Riis A, Christensen S, Nørgaard M, Sørensen HT. Diabetes and 30-day mortality from peptic ulcer bleeding and perforation: a Danish population-based cohort study. Diabetes Care. 2006;29(4):805-810.

9. Sung JJ, Tsoi KK, Ma TK, Yung MY, Lau JY, Chiu PW. Causes of mortality in patients with peptic ulcer bleeding: a prospective cohort study of 10,428 cases. Am J Gastroenterol. 2010;105(1):84-89.

10. Zullo A, Hassan C, Campo SM, Morini S. Bleeding peptic ulcer in the elderly: risk factors and prevention strategies. Drugs Aging. 2007;24(10):815-828.

11. Hung LC, Ching JY, Sung JJ, et al. Long-term outcome of Helicobacter pylori-negative idiopathic bleeding ulcers: a prospective cohort study. Gastroenterology. 2005;128(7):1845-1850.

12. Hilton D, Iman N, Burke GJ, et al. Absence of abdominal pain in older persons with endoscopic ulcers: a prospective study. $\mathrm{Am} \mathrm{J}$ Gastroenterol. 2001;96(2):380-384.

13. Wang JK, Wang RT. [Meta-analysis on the epidemiology of Helicobacter pylori infection in China]. Zonghua Liu Xing Bing Xue Za Zhi. 2003;24(6):443-446. Chinese.

14. Li Z, Zou D, Ma X, et al. Epidemiology of peptic ulcer disease: endoscopic results of the systematic investigation of gastrointestinal disease in China. Am J Gastroenterol. 2010;105(12):2570-2577.

15. Wolosin JD, Gertler SL, Peterson WL, Sandersfeld MA, Isenberg JI. Gastric ulcer recurrence: follow-up of a double-blind, placebo-controlled trial. J Clin Gastroenterol. 1989;11(1):12-16.

16. Malfertheiner P, Megraud F, O’Morain C, et al. Current concepts in the management of Helicobacter pylori infection: the Maastricht III Consensus Report. Gut. 2007;56(6):772-781.

17. Chey WD, Wong BC; Practice Parameters Committee of the American College of Gastroenterology. American College of Gastroenterology guideline on the management of Helicobacter pylori infection. Am J Gastroenterol. 2007;102(8):1808-1825.

18. Katelaris PH, Forbes GM, Talley NJ, Crotty B. A randomized comparison of quadruple and triple therapies for Helicobacter pylori eradication: The QUADRATE study. Gastroenterology. 2002;123(6):1763-1769.

19. Gené E, Calvet X, Azagra R, Gisbert JP. Triple vs quadruple therapy for treating Helicobacter pylori infection: a meta-analysis. Aliment Pharmacol Ther. 2003;17(9):1137-1143.

20. Calvet X, García N, López T, Gisbert JP, Gené E, Roque M. A metaanalysis of short versus long therapy with a proton pump inhibitor, clarithromycin and either metronidazole or amoxycillin for treating Helicobacter pylori infection. Aliment Pharmacol Ther. 2000;14(5): 603-609. 
21. Fuccio L, Minardi ME, Zagari RM, Grilli D, Magrini N, Bazzoli F. Meta-analysis: duration of first-line proton-pump inhibitor based triple therapy for Helicobacter pylori eradication. Ann Intern Med. 2007;147(8):553-562.

22. Tankovic J, Lamarque D, Lascols C, Soussy CJ, Delchier JC. Impact of Helicobacter pylori resistance to clarithromycin on the efficacy of the omeprazole-amoxicillin-clarithromycin therapy. Aliment Pharmacol Ther. 2001;15(5);707-713.

23. Megraud F, Lamouliatte $H$. Review article: the treatment of refractory Helicobacter pylori infection. Aliment Pharmacol Ther. 2003;17(11): 1333-1343.

24. Wu DC, Hsu PI, Wu JY, et al. Sequential and concomitant therapy with 4 drugs are equally effective for eradication of $\mathrm{H}$ pylori infection. Clin Gastroenterol Hepatol. 2010;8(1):36-41. e1.

25. Malfertheiner P, Megraud F, O'Morain CA, et al; European Helicobacter Study Group. Management of Helicobacter pylori infection - the Maastricht IV/Florence Consensus Report. Gut. 2012;61(5):646-664.

26. Silverstein FE, Faich G, Goldstein JL, et al. Gastrointestinal toxicity with celecoxib vs nonsteroidal anti-inflammatory drugs for osteoarthritis and rheumatoid arthritis: the CLASS study: a randomized controlled trial. Celecoxib Long-term Arthritis Safety Study. JAMA. 2000;284(10): $1247-1255$.

27. Lanza FL, Chan FK, Quigley EM; Practice Parameters Committee of the American College of Gastroenterology. Guidelines for prevention of NSAID-related ulcer complications. Am J Gastroenterol. 2009;104(3):728-738.

28. Griffin MR, Piper JM, Daugherty JR, Snowden M, Ray WA. Nonsteroidal anti-inflammatory drug use and increased risk for peptic ulcer disease in elderly persons. Ann Intern Med. 1991;114(4):257-263.

29. Chan FK, To KF, Wu JC, et al. Eradication of Helicobacter pylori and risk of peptic ulcers in patients starting long-term treatment with nonsteroidal anti-inflammatory drugs: a randomized trial. Lancet. 2002;359(9300):9-13.

30. Rostom A, Dube C, Wells G, et al. Prevention of NSAID-induced gastroduodenal ulcers. Cochrane Database Syst Rev. 2002;(4): CD002296.

31. Leontiadis GI, Sreedharan A, Dorward S, et al. Systematic reviews of the clinical effectiveness and cost-effectiveness of proton pump inhibitors in acute upper gastrointestinal bleeding. Health Technol Assess. 2007;11(51):iii-iv, 1-164.

32. Rostom A, Muir K, Dubé C, et al. Gastrointestinal safety of cyclooxygenase-2 inhibitors:a Cochrane Collaboration systematic review. Clin Gastroenterol Hepatol. 2007;5(7):818-828, 828.e1.

33. Kearney PM, Baigent C, Godwin J, Halls H, Emberson JR, Patrono C. Do selective cyclo-oxygenase-2 inhibitors and traditional non-steroidal anti-inflammatory drugs increase the risk of atherothrombosis? Metaanalysis of randomized trials. BMJ. 2006;332(7553):1302-1308.

34. McGettigan P, Henry D. Cardiovascular risk and inhibition of cyclooxygenase: a systematic review of the observational studies of selective and nonselective inhibitors of cyclooxygenase 2. JAMA. 2006;296(13):1633-1644.

35. Lanas A, Fuentes J, Benito R, Serrano P, Bajador E, Sáinz R. Helicobacter pylori increases the risk of upper gastrointestinal bleeding in patients taking low-dose aspirin. Aliment Pharmacol Ther. 2002;16(4):779-786.

36. Malfertheiner P, Chan FK, McColl KE. Peptic ulcer disease. Lancet. 2009;374(9699):1449-1461.

37. Moukarbel GV, Signorovitch JE, Pfeffer MA, et al. Gastrointestinal bleeding in high risk survivors of myocardial infarction: the VALIANT Trial. Eur Heart J. 2009;30(18):2226-2232.

38. Chan FK, Chung SC, Suen BY, et al. Preventing recurrent upper gastrointestinal bleeding in patients with Helicobacter pylori infection who are taking low-dose aspirin or naproxen. $N$ Engl J Med. 2001;344(13): 967-973.

39. Chan FK, Ching JY, Suen BY, Tse YK, Wu JC, Sung JJ. Effects of Helicobacter pylori infection on long-term risk of peptic ulcer bleeding in low-dose aspirin users. Gastroenterology. 2013;144(3):528-535.
40. Chan FK, Ching JY, Hung LC, et al. Clopidogrel versus aspirin and esomeprazole to prevent recurrent ulcer bleeding. $N$ Engl J Med. 2005;352(3):238-244.

41. Lai KC, Chu KM, Hui WM, et al. Esomeprazole with aspirin versus clopidogrel for prevention of recurrent gastrointestinal ulcer complications. Clin Gastroenterol Hepatol. 2006;4(7):860-865.

42. Bhatt DL, Scheiman J, Abraham NS, et al; American College of Cardiology Foundation Task Force on Clinical Expert Consensus Documents. ACCF/ACG/AHA 2008 expert consensus document on reducing the gastrointestinal risks of antiplatelet therapy and NSAID use: a report of the American College of Cardiology Foundation Task Force on Clinical Expert Consensus Documents. J Am Coll Cardiol. 2008;52(18):1502-1517.

43. Yusuf S, Zhao F, Mehta SR, Chrolavicius S, Tognoni G, Fox KK; Clopidogrel in Unstable Angina to Prevent Recurrent Events Trial Investigators. Effects of clopidogrel in addition to aspirin in patients with acute coronary syndromes without ST-segment elevation. $N$ Engl J Med. 2001;345(7):494-502.

44. Connolly SJ, Pogue J, Hart RG, et al; ACTIVE Investigators. Effect of clopidogrel added to aspirin in patients with atrial fibrillation. $N$ Engl J Med. 2009;360(20):2066-2078.

45. Bhatt DL, Cryer BL, Contant CF, et al; COGENT Investigators. Clopidogrel with or without omeprazole in coronary artery disease. N Engl J Med. 2010;363(20):1909-1917.

46. Gilard M, Arnaud B, Cornily JC, et al. Influence of omeprazole on the antiplatelet action of clopidogrel associated with aspirin:the randomized, double-blind OCLA (Omeprazole Clopidogrel Aspirin) study. J Am Coll Cardiol. 2008;51(3):256-260.

47. Li XQ, Andersson TB, Ahlström M, Weidolf L. Comparison of inhibitory effects of the proton pump-inhibiting drugs omeprazole, esomeprazole, lansoprazole, pantoprazole, and rabeprazole on human cytochrome P450 activities. Drug Metab. Dispos. 2004;32(8):821-827.

48. Juurlink DN, Gomes T, Ko DT, et al. A population-based study of the drug interaction between proton pump inhibitors and clopidogrel. CMAJ. 2009;180(7):713-718.

49. Kwok CS, Loke YK. Meta-analysis: the effects of proton pump inhibitors on cardiovascular events and mortality in patients receiving clopidogrel. Aliment Pharmacol Ther. 2010;31(8):810-823.

50. Becker RC, Scheiman J, Dauerman HL, et al; American College of Cardiology; American College of Gastroenterology. Management of platelet-directed pharmacotherapy in patients with atherosclerotic coronary artery disease undergoing elective endoscopic gastrointestinal procedures. J Am Coll Cardiol. 2009;54(24):2261-2276.

51. Chan FK. Anti-platelet therapy and managing ulcer risk. J Gastroenterol Hepatol. 2012;27(2):195-199.

52. Ciociola AA, McSorley DJ, Turner K, Sykes D, Palmer JB. Helicobacter pylori infection rates in duodenal ulcer patients in the United States may be lower than previously estimated. Am J Gastroenterol. 1999;94(7): $1834-1840$

53. Wong GL, Wong VW, Chan Y, et al. High incidence of mortality and recurrent bleeding in patients with Helicobacter pylori-negative idiopathic bleeding ulcers. Gastroenterology. 2009;137(2):525-531.

54. Wong GL, Au KW, Lo AO, et al. Gastroprotective therapy does not improve outcomes of patients with Helicobacter pylori-negative idiopathic bleeding ulcers. Clin Gastroenterol Hepatol. 2012;10(10): $1124-1129$

55. Vakil N, van Zanten SV, Kahrilas P, Dent J, Jones R; Global Consensus Group. The Montreal definition and classification of gastroesophageal reflux disease: a global evidence-based consensus. Am J Gastroenterol. 2006;101(8):1900-1920.

56. Wu JC. Gastroesophageal reflux disease: an Asian perspective. J Gastroenterol Hepatol. 2008;23(12):1785-1793.

57. Dent J, El-Serag HB, Wallander MA, Johansson S. Epidemiology of gastro-oesophageal reflux disease: a systematic review. Gut. 2005;54(5): 710-717.

58. Kang JY. Systematic review: geographical and ethnic differences in gastro-oesophaeal reflux disease. Aliment Pharmacol Ther. 2004;20(7): $705-717$. 
59. Räihä IJ, Impivaara O, Seppälä M, Sourander LB. Prevalence and characteristics of symptomatic gastroesophageal reflux in the elderly. J Am Geriatr Soc. 1992;40(12):1209-1211.

60. Mold JW, Reed LE, Davis AB, Allen ML, Decktor DL, Robinson M. Prevalence of gastroesophageal reflux in the elderly patients in a primary care setting. Am J Gastroenterol. 1991;86(8):965-970.

61. Collen MJ, Abdulian JD, Chen YK. Gastroesophageal reflux disease in the elderly: More severe disease that require aggressive therapy. Am J Gastroenterol. 1995;90(7):1053-1057.

62. el-Serag HB, Sonnenberg A. Association between different forms of gastro-oesophageal reflux disease. Gut. 1997;41(5):594-599.

63. Amano K, Adachi K, Katsube T, Watanabe M, Kinoshita Y. Role of hiatus hernia and gastric mucosal atrophy in the development of reflux esophagitis in the elderly. J Gastroenterol Hepatol. 2001;16(2): 132-136.

64. Cameron AJ. Barrett's esophagus: prevalence and size of hiatal hernia. Am J Gastroenterol. 1999;94(8):2054-2059.

65. Corley DA, Kubo A. Body mass index and gastroesophageal reflux disease: a systematic review and meta-analysis. Am J Gastroenterol. 2006;101(11):2619-2628.

66. Wu JC, Mui LM, Cheung CM, Chan Y, Sung JJ. Obesity is associated with increased transient lower esophageal sphincter relaxation. Gastroenterology. 2007;132(3):883-889.

67. Haruma K, Hamada H, Mihara M, et al. Negative association between Helicobacter pylori and reflux esophagitis in older patients: case-control study in Japan. Helicobacter. 2000;5(1):24-29.

68. Wu JC, Sung JJ, Ng EK, et al. Prevalence and distribution of Helicobacter pylori in gastroesophageal reflux disease:a study from the East. Am J Gastroenterol. 1999;94(7):1790-1794.

69. O'Connor HJ. Review article: Helicobacter pylori and gastrooesophageal reflux disease- clinical implications and management. Aliment Pharmacol Ther. 1999;13(2):117-127.

70. Koike T, Ohara S, Sekine H, et al. Increased gastric acid secretion after Helicobacter pylori eradication may be a factor for developing reflux esophagitis. Aliment Pharmacol Ther. 2001;15(6):813-820.

71. Wu JC, Lai AC, Wong SK, Chan FK, Leung WK, Sung JJ. Dysfunction of oesophageal motility in Helicobacter pylori-infected patients with reflux esophagitis. Aliment Pharmacol Ther. 2001;15(12):1913-1919.

72. Franceschi M, Di Mario F, Leandro G, Maggi S, Pilotto A. Acid-related disorders in the elderly. Best Pract Res Clin Gastroenterol. 2009;23(6): 839-848.

73. Räihä I, Hietanen E, Sourander L. Symptoms of gastro-oesophageal reflux disease in elderly patients. Age Ageing. 1991;20(5):365-370

74. Xia HH, Lai KC, Lam SK, et al. Symptomatic response to lansoprazole predicts abnormal acid reflux in endoscopy-negative patients with noncardiac chest pain. Aliment Pharmacol Ther. 2003;17(3):369-377.

75. Sontag S. The medical management of reflux esophagitis. Role of antacids and acid inhibition. Gastroenterol Clin North Am. 1990;19(3): 673-690.

76. Shi S, Klotz U. Proton pump inhibitors: an update of their clinical use and clinical pharmacokinetics. Eur J Clin Pharmacol. 2008;64(10): 935-951.

77. Johnson DA. Review of esomeprazole in the treatment of acid disorders. Expert Opin Pharmacother. 2003;4(2):253-264.

78. Andersson T, Röhss K, Bredberg E, Hassan-Alin M. Pharmacokinetics and pharmacodynamics of esomeprazole, the S-isomer of omeprazole. Aliment Pharmacol Ther. 2001;15(10):1563-1569.

79. Sostek M, Chen Y, Andersson T. Effect of timing of dosing in relation to food intake on the pharmacokinetics of esomeprazole. $\mathrm{Br} J$ Clin Pharmacol. 2007;64(3):386-390.

80. Hasselgren G, Hassan-Alin M, Andersson T, Claar-Nilsson C, Röhss K. Pharmacokinetics study of esomeprazole in the elderly. Clin Pharmacokinet. 2001;40(2):145-150.

81. Castell DO, Kahrilas PJ, Richter JE, et al. Esomeprazole (40 mg) compared with lansoprazole $(30 \mathrm{mg})$ in the treatment of erosive esophagitis. Am J Gastroenterol. 2002;97(3):575-583.
82. Kahrilas PJ, Falk GW, Johnson DA, et al. Esomeprazole improves healing and symptom resolution as compared with omeprazole in reflux oesophagitis patients: a randomized controlled trial. Aliment Pharmacol Ther. 2000;14(10):1249-1258.

83. Richter JE, Kahrilas PJ, Johanson J, et al; Esomeprazole Study Investigators. Efficacy and safety of esomeprazole compared with omeprazole in GERD patients with erosive esophagitis: a randomized controlled trial. Am J Gastroenterol. 2001;96(3):656-665.

84. Fennerty MB, Johanson JF, Hwang C, Sostek M. Efficacy of esomeprazole $40 \mathrm{mg}$ vs lansoprazole $30 \mathrm{mg}$ for healing moderate to severe erosive oesophagitis. Aliment Pharmacol Ther. 2005;21(4):455-463.

85. Gillessen A, Beil W, Modlin IM, Gatz G, Hole U. $40 \mathrm{mg}$ pantoprazole and $40 \mathrm{mg}$ esomeprazole are equivalent in the healing of esophageal lesions and relief from gastroesophageal reflux disease-related symptoms. J Clin Gastroenterol. 2004;38(4):332-340.

86. Howden CW, Ballard ED 2nd, Robieson W. Evidence for therapeutic equivalence of lansoprazole $30 \mathrm{mg}$ and esomeprazole $40 \mathrm{mg}$ in the treatment of erosive oesophagitis. Clin Drug Investig. 2002;22(2): 99-109.

87. Labenz J, Armstrong D, Lauritsen K, et al; Expo Study Investigators. A randomized comparative study of esomeprazole $40 \mathrm{mg}$ versus pantoprazole $40 \mathrm{mg}$ for healing erosive oesophagitis: the EXPO study. Aliment Pharmacol Ther. 2005;21(6):739-746.

88. Lightdale CJ, Schmitt C, Hwang C, Hamelin B. A multicenter, randomized, double-blind, 8-week comparative trial of low-dose esomeprazole $(20 \mathrm{mg})$ and standard-dose omeprazole $(20 \mathrm{mg})$ in patients with erosive esophagitis. Dig Dis Sci. 2006;51(5):852-857.

89. Maton PN, Vakil NB, Levine JG, et al; Esomeprazole Study Investigators. Safety and efficacy of long-term esomeprazole therapy in patients with healed erosive oesophagitis. Drug Saf. 2001;24(8):625-635.

90. Devault KR, Johanson JF, Johnson DA, Liu S, Sostek MB. Maintenance of healed erosive esophagitis:a randomized six-month comparison of esomeprazole twenty milligrams with lansoprazole fifteen milligrams. Clin Gastroenterol Hepatol. 2006;4(7):852-859.

91. Lauritsen K, Devière J, Bigard MA, et al. Esomeprazole $20 \mathrm{mg}$ and lansoprazole $15 \mathrm{mg}$ in maintaining healed reflux oesophagitis: Metropole study results. Aliment Pharmacol Ther. 2003;17 Suppl 1:24; discussion 25-27.

92. Labenz J, Armstrong D, Lauritsen K, et al. Esomeprazole $20 \mathrm{mg}$ vs pantoprazole $20 \mathrm{mg}$ for maintenance therapy of healed erosive oesophagitis: results from the EXPO study. Aliment Pharmacol Ther. 2005;22(9): 803-811.

93. Armstrong D, Talley NJ, Lauritsen K, et al. The role of acid suppression in patients with endoscopy-negative reflux disease: the effect of treatment with esomeprazole or omeprazole. Aliment Pharmacol Ther. 2004;20(4):413-421.

94. Katz PO, Castell DO, Levine D. Esomeprazole resolves chronic heartburn in patients without erosive esophagitis. Aliment Pharmacol Ther. 2003;18(9):875-882.

95. Pace F, Tonini M, Pallotta S, Molteni P, Porro GB. Systematic review: maintenance treatment of gastro-oesophageal reflux disease with proton pump inhibitors taken 'on-demand'. Aliment Pharmacol Ther. 2007;26(2):195-204.

96. Laine L. Review article: esomeprazole in the treatment of Helicobacter pylori. Aliment Pharmaco Ther. 2002;16 Suppl 4:115-118.

97. Goldstein JL, Johanson JF, Suchower LJ, Brown KA. Healing of gastric ulcers with esomeprazole versus ranitidine in patients who continued to receive NSAID therapy: a randomized trial. Am J Gastroenterol. 2005;100(12):2650-2657.

98. Scheiman JM, Yeomans ND, Talley NJ, et al. Prevention of ulcers by esomeprazole in at-risk patients using non-selective NSAIDs and COX-2 inhibitors. Am J Gastroenterol. 2006;101(4):701-710.

99. Scheiman JM, Devereaux PJ, Herlitz J, et al. Prevention of peptic ulcers with esomeprazole in patients at risk of ulcer development treated with low-dose acetylsalicylic acid: a randomised, controlled trial (OBERON). Heart. 2011;97(10):797-802. 
100. Sung JJ, Barkun A, Kuipers EJ, et al; Peptic Ulcer Bleed Study Group. Intravenous esomeprazole for prevention of recurrent peptic ulcer bleeding: a randomized trial. Ann Intern Med. 2009;150(7):455-464.

101. Recker RR. Calcium absorption and achlorhydria. $N$ Engl J Med. 1985;313(2):70-73.

102. Mizunashi K, Furukawa Y, Katano K, Abe K. Effect of omeprazole, an inhibitor of $\mathrm{H}+, \mathrm{K}(+)$-ATPase, on bone resorption in humans. Calcif Tissue Int. 1993;53(1):21-25.

103. Yang YX, Lewis JD, Epstein S, Metz DC. Long-term proton pump inhibitor therapy and risk of hip fracture. JAMA. 2006;296(24): 2947-2953

104. Yu EW, Bauer SR, Bain PA, Bauer DC. Proton pump inhibitors and risk of fractures:a meta-analysis of 11 international studies. Am J Med. 2011;124(6):519-526.

105. García Rodríguez LA, Ruigómez A, Panés J. Use of acid-suppressing drugs and the risk of bacterial gastroenteritis. Clin Gastroenterol Hepatol. 2007;5(12):1418-1423.

106. Dial S, Delaney JA, Barkun AN, Suissa S. Use of gastric acidsuppressive agents and the risk of community-acquired Clostridium difficile-associated disease. JAMA. 2005;294(23):2989-2995.

107. Leonard J, Marshall JK, Moayyedi P. Systematic review of the risk of enteric infection in patients taking acid suppression. Am J Gastroenterol. 2007;102(9):2047-2056; quiz 2057.

108. Kwok CS, Arthur AK, Anibueze CI, Singh S, Cavallazzi R, Loke YK. Risk of Clostridium difficile infection with acid suppressing drugs and antibiotics: meta-analysis. Am J Gastroenterol. 2012;107(7): 1011-1019.

109. Janarthanan S, Ditah I, Adler DG, Ehrinpreis MN. Clostridium difficile-associated diarrhea and proton pump inhibitor therapy: a meta-analysis. Am J Gastroenterol. 2012;107(7):1001-1010.

110. Campbell MS, Obstein K, Reddy KR, Yang YX. Association between proton pump inhibitor use and spontaneous bacterial peritonitis. Dig Dis Sci. 2008;53(2):394-398.

111. Bajaj JS, Zadvornova Y, Heuman DM, et al. Association of proton pump inhibitor therapy with spontaneous bacterial peritonitis in cirrhotic patients with ascites. Am J Gastroenterolol. 2009;104(5): 1130-1134.

112. Trikudanathan G, Israel J, Cappa J, O'Sullivan DM. Association between proton pump inhibitors and spontaneous bacterial peritonitis in cirrhotic patients - a systematic review and meta-analysis. Int J Clin Pract. 2011;65(6):674-678.

113. Laheij RJ, Sturkenboom MC, Hassing RJ, Dieleman J, Stricker BH, Jansen JB. Risk of community-acquired pneumonia and use of gastric acid-suppressive drugs. JAMA. 2004;292(16):1955-1960.
114. Gulmez SE, Holm A, Frederiksen H, Jensen TG, Pedersen C, Hallas J. Use of proton pump inhibitors and the risk of community-acquired pneumonia: a population-based case-control study. Arch Intern Med. 2007;167(9):950-955.

115. Sarkar M, Hennessy S, Yang YX. Proton-pump inhibitor use and the risk for community-acquired pneumonia. Ann Intern Med. 2008;149(6):391-398.

116. Jena AB, Sun E, Goldman DP. Confounding in the association of proton pump inhibitor use with risk of community-acquired pneumonia. J Gen Intern Med. 2013;28(2):223-230.

117. Marcuard SP, Albernaz L, Khazanie PG. Omeprazole therapy causes malabsorption of cyanocobalamin (vitamin B12). Ann Intern Med. 1994;120(3):211-215.

118. Valuck RJ, Ruscin JM. A case-control study on adverse effects: $\mathrm{H} 2$ blocker or proton pump inhibitor use and risk of vitamin B12 deficiency in older adults. J Clin Epidemiol. 2004;57(4):422-428.

119. Hirschowitz BI, Worthington J, Mohnen J. Vitamin B12 deficiency in hypersecretors during long-term acid suppression with proton pump inhibitors. Aliment Pharmacol Ther. 2008;27(11):1110-1121.

120. Epstein M, McGrath S, Law F. Proton-pump inhibitors and hypomagnesemic hypoparathyroidism. N Engl J Med. 2006;355(17): 1834-1836.

121. Cundy T, Dissanayake A. Severe hypomagnesaemia in long-term users of proton-pump inhibitors. Clin Endocrinol (Oxf). 2008;69(2) 338-341.

122. Centanni M, Gargano L, Canettieri G, et al. Thyroxine in goiter, Helicobacter pylori infection, and chronic gastritis. $N$ Engl J Med. 2006;354(17):1787-1795.

123. Kuipers EJ, Lundell L, Klinkenberg-Knol EC, et al. Atrophic gastritis and Helicobacter pylori infection in patients with reflux esophagitis treated with omeprazole or fundoplication. $N$ Engl J Med. 1996;334(16):1018-1022.

124. Sung JJ, Lin SR, Ching JY, et al. Atrophy and intestinal metaplasia one year after cure of $\mathrm{H}$. pylori infection: a prospective, randomized study. Gastroenterology. 2000;119(1):7-14.

125. Fock KM, Talley NJ, Fass R, et al. Asia-Pacific consensus on the management of gastroesophageal reflux disease: update. J Gastroenterol Hepatol. 2008;23(1):8-22.

126. Frelinger AL 3rd, Lee RD, Mulford DJ, et al. A randomized, 2-period, crossover design study to assess the effects of dexlansoprazole, lansoprazole, esomeprazole, and omeprazole on the steady-state pharmacokinetics and pharmacodynamics of clopidogrel in healthy volunteers. J Am Coll Cardiol. 2012;59(14):1304-1311.
Clinical Interventions in Aging

\section{Publish your work in this journal}

Clinical Interventions in Aging is an international, peer-reviewed journal focusing on evidence-based reports on the value or lack thereof of treatments intended to prevent or delay the onset of maladaptive correlates of aging in human beings. This journal is indexed on PubMed Central, MedLine, the American Chemical Society's 'Chemical Abstracts

\section{Dovepress}

Service' (CAS), Scopus and the Elsevier Bibliographic databases. The manuscript management system is completely online and includes a very quick and fair peer-review system, which is all easy to use. Visi http://www.dovepress.com/testimonials.php to read real quotes from published authors. 